\title{
Study on the combustion behavior of high impact polystyrene nanocomposites produced by different extrusion processes
}

\author{
G. Sanchez-Olivares ${ }^{1}$, A. Sanchez-Solis ${ }^{1}$, G. Camino $^{2}$, O. Manero ${ }^{1}$ \\ ${ }^{1}$ Instituto de Investigaciones en Materiales, Universidad Nacional Autónoma de México. A.P. 70-360, Mexico, D. F., \\ 04510, Mexico \\ ${ }^{2}$ Politecnico di Torino - Sede di Alessandria, Viale Teresa Michel 5, 15100 Alessandria, Italy
}

Received 15 May 2008; accepted in revised form 9 July 2008

\begin{abstract}
The combustion behavior of a blend made of high impact polystyrene (HIPS) with sodium montmorillonite $\left(\mathrm{MMT}-\mathrm{Na}^{+}\right)$and triphenyl phosphite (TPP), as a halogen-free flame retardant, is analyzed in detail in this work. The blend is processed through various extrusion methods aimed to improve clay dispersion. The UL94 method in vertical position, oxygen index and cone calorimetric measurements assess HIPS blend behavior in combustion. TGA, FTIR, SEM and X-ray measurements, together with mechanical and rheological tests evaluate the thermal degradation, morphology, intercalation and degree of dispersion of particles. The use of a static-mixing die placed at the extreme of a single screw extruder improves clay platelets distribution and reduces the peak heat release rate better than employing a twin screw extrusion process. In addition, mechanical and rheological properties are affected substantially by changing the extrusion process. A correlation between clay dispersion and HIPS fire retardant properties is found, as the peak heat release rate decreases with good clay dispersion in cone calorimetric tests.
\end{abstract}

Keywords: nanocomposites, thermal properties, rheology, HIPS, TPP

\section{Introduction}

The combustion behavior of polymeric materials has been given attention due to its implications in safety for various industrial sectors. Polymer behavior under combustion is usually tested employing the oxygen index [1] and the UL94 [2] standard, and its behavior under forced combustion is commonly evaluated in cone calorimetric [3-5] tests.

To reduce the polymer combustion, various materials have been developed, such as flame retardant additives. In the past, these materials were halogenbased [6-10], but a major setback to their fire-retardant action is the production of toxic and corrosive vapors with optically dense smokes. Alternative materials sought to substitute the use of halogenbased additives include those phosphorous-based [11], and recently polymer nanocomposites [1216]. The fact that combustion is reduced in the presence of nanoparticles with less generation of toxic compounds and enhanced barrier, thermal and mechanical properties of the polymer matrix, has motivated research on nanocomposite additives $[17,18]$.

Procedures to obtain polymer nanocomposites include in-situ polymerization and melt mixing extrusion among others. The latter presents advantages such as the use of commercially available equipment for large volume capacities. The melt extrusion process applied to the production of

*Corresponding author, e-mail: sancheza@servidor.unam.mx

(C) BME-PT and GTE 
nanocomposites requires the control of various factors, such as the shear stress, residence time, affinity of the particles to the polymer matrix and screw configuration [19-23].

In particular, high impact polystyrene (HIPS) presents high impact resistance but is a highly-flammable material. In a recent study on the HIPS rate of combustion [24], it was found that, contrary to what was expected, the addition of sodium montmorillonite $\left(\mathrm{MMT}-\mathrm{Na}^{+}\right)$nanoparticles increases the burning rate. However, when they are blended with triphenyl phosphite (TPP), the burning rate is decreased considerably.

The main objective of this work is the analysis of the processes aimed to reduce the flammability properties of HIPS with the use of clays and a nonhalogenated flame-retardant additive, maintaining the original mechanical properties of HIPS, mainly the impact resistance. The use of different extrusion processes is intended to improve the clay and flame-retardant agent dispersion to reduce the HIPS flammability. The extrusion processes considered include intermeshing counter-rotating twin-screw, single-screw with a static-mixing die and the latter with sonication transducers placed on the die itself.

\section{Experimental part}

\subsection{Materials}

High impact polystyrene (HIPS) from Resirene, MEXICO had a density of $1.05 \mathrm{~g} / \mathrm{cm}^{3}$ (according to ASTM D792 norm) a melting temperature of $220^{\circ} \mathrm{C}$, a glass-transition temperature of $100^{\circ} \mathrm{C}$ (as determined by DSC with a heating rate of $10^{\circ} \mathrm{C} / \mathrm{min}$ under nitrogen atmosphere) and a melt index $2.5 \mathrm{~g} / 10 \mathrm{~min}$ (according to ASTM D1238). Butadiene content is $15 \mathrm{wt} \%$ (as determined by thermogravimetry (TGA), at a heating rate of $2^{\circ} \mathrm{C} / \mathrm{min}$ under nitrogen). Sodium montmorillonite clay $\left(\mathrm{MMT}-\mathrm{Na}^{+}\right)$was provided by Nanocor, Inc, USA (ionic exchange capacity of $135 \mathrm{meq} / 100 \mathrm{~g}$ ). Triphenyl phosphite (TPP), an uncolored liquid with density of $1.184 \mathrm{~g} / \mathrm{ml}$ at $25^{\circ} \mathrm{C}$ was provided by Crompton Corporation, USA, and used as received.

\subsection{Equipment}

A conical twin-screw intermeshing counter-rotating extruder (Haake Rheocord 90 TW-100) of $331 \mathrm{~mm}$ length with $31.1 \mathrm{~mm}$ initial diameter and
$19.7 \mathrm{~mm}$ end diameter, and a single screw extruder with $20 \mathrm{~mm}$ diameter ( $L / D$ ratio of 27$)$ with a static mixing die, which had conical compression and depression sections to produce extensional flows, were used to prepare the HIPS blends. Four 50 watts piezoelectric elements at a frequency of $25 \mathrm{~Hz}$ are attached to the die to produce sonication waves. Drying of samples before processing was carried out in a Pagani dehumidifier at $100^{\circ} \mathrm{C}$ during $8 \mathrm{~h}$. A Demag-Ergotech 50-200 ( $L / D$ ratio of 20) mould-injection machine was used to produce specimens for UL94 vertical position tests and for mechanical properties. Specimens for oxygen index and cone calorimeter tests were obtained by compression molding in a Laboratory Press Gibitre Instrument. Cone calorimeter tests were carried out in a Fire Testing Technology (FTT) cone calorimeter apparatus in the horizontal position. Tensile properties were measured in an Instron 1125 machine under a constant strain-rate of $50 \mathrm{~mm} / \mathrm{min}$ according to ASTM D638. Impact tests were performed following ASTM D256 Izod-notched type. XRD-analyses were performed on compressionmolded $30 \times 30 \times 0.5 \mathrm{~mm}$ samples with a Thermo ARL diffractometer $\mathrm{X}$-tra 48 using $\mathrm{Cu}-\mathrm{K}_{\alpha} \mathrm{X}$-ray source $(\lambda=1.540562 \AA)$, step-size $0.02^{\circ}$ at $2^{\circ} \cdot \mathrm{min}^{-1}$ scanning rate in the range $2-10^{\circ}$. Combined thermogravimetry/Fourier transform infrared (TGA/ FTIR) studies were carried out using a Perkin Elmer Pyris 1 thermogravimetric analyzer interfaced to a Perkin Elmer Spectrum GX Fourier transform infrared spectrophotometer at a scan rate of $10^{\circ} \mathrm{C} / \mathrm{min}$ under inert (nitrogen) gas flow $(30.0 \mathrm{cc} / \mathrm{min})$. Rheological properties were measured on a TA Instrument AR-1000-N controlled stress rheometer with parallel plates of $25 \mathrm{~mm}$ diameter. Element mapping analysis were taken on a fractured surface with an Electronic Microscopic scanning LEO Model LEO1450VP (s/n CS-2278) and EDS with a Microson Oxford Inca Energy 200 (s/n CS2207).

\subsection{Procedure}

To evaluate the dispersion and distribution of the clay particles and TPP in the HIPS matrix, three extrusion processes were considered: intermeshing counter-rotating twin-screw, single-screw with a static-mixing die and single screw with the same die and sonication transducers attached to the die. 
The purpose to use the static mixer was to produce strong extensional flows intended to improve the particle dispersion and its distribution in the polymer matrix. The blend composition is HIPS plus $5 \mathrm{phr}$ clay and $5 \mathrm{phr}$ TPP (HIPS-TPP/clay). The procedure to obtain the blends is described as follows:

1. Dried clay, $\sim 1 \%$ residual water measured in a KERN MLB 50-3 powder dryer equipment, and TPP were mixed (1:1) under continuous stirring maintained at $90-105^{\circ} \mathrm{C}$ to render a homogeneous suspension (TPP/clay).

2. This blend and HIPS were fed using a top feeder equipment attached to the extruder under the following conditions:

a) Counter-rotating intermeshing twin-screw extrusion (CR-TS). Rotation speed was $70 \mathrm{rpm}$ at processing temperature of $190^{\circ} \mathrm{C}$.

b) Single-screw extrusion with the static mixing die (SS-SMD). Rotational speed was $30 \mathrm{rpm}$ at $255^{\circ} \mathrm{C}$

c) Single-screw extrusion with four sonication transducers each one with $50 \mathrm{~W}$ power attached to the static mixing die (SS-SMD-U). The frequency generator was set at $25 \mathrm{~Hz}$. Processing temperature was $255^{\circ} \mathrm{C}$ with rotational speed of $30 \mathrm{rpm}$.

\section{Results and discussion}

\subsection{X-ray and element mapping}

Figure 1 shows the X-ray patterns of both the TPPclay system and the HIPS-TPP/clay blends. The diffraction peak of the TPP-clay system appears. In contrast, the HIPS-TPP/clay blends prepared following the three extrusion processes present a similar spectrum with absence of diffraction peaks in the range $2 \theta=2-10^{\circ}$ revealing some intercalation that might have occurred during mixing.

According to the element mapping analysis (Figure 2), the blend processed via single-screw with the static mixing die (Figures $2 \mathrm{a}$ and $2 \mathrm{~b}$ ) and with sonication (Figures $2 \mathrm{c}$ and $2 \mathrm{~d}$ ) show dispersed agglomerates containing mainly silicon atoms. TPP distribution obtained after the single-screw extrusion (Figures 2a-2d) shows phosphorous and silicon containing particles in similar patterns. On the other hand, with the twin-screw extrusion (Figure 2e), no phosphorous particles are detected, indicating that TPP is not dispersed, but presumably

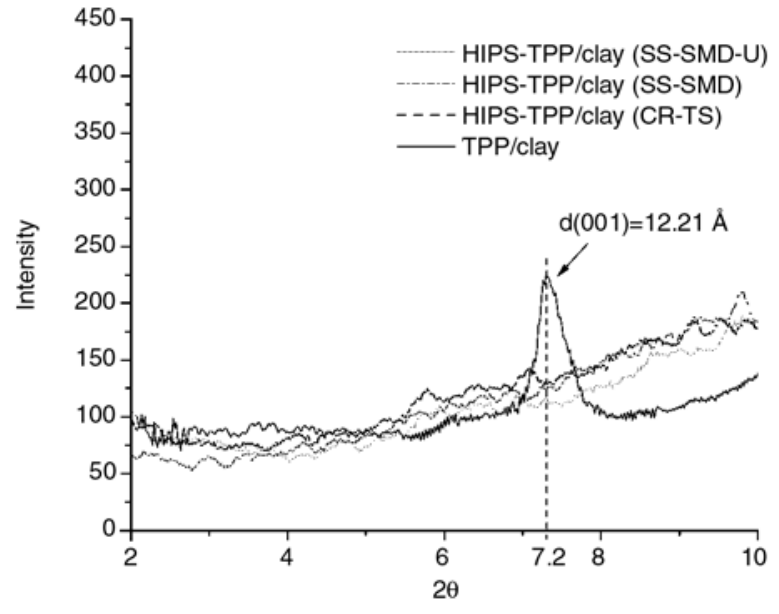

Figure 1. X-ray analysis of the HIPS-TPP/clay blend. (CR-TS), twin screw counter-rotating; (SS-SMD), single screw with the static mixing die; (SS-SMD-U) single screw with the static mixing die and sonication.

lies inside the micron-size clay agglomerates. Consequently, TPP distribution depends on the dispersion pattern of the clay particles. These results indicate that the extensional stresses generated in the static mixing die improve clay and hence TPP dispersion, as compared to the twin-screw extrusion results.

\subsection{TPP/clay blend}

The thermal stability and degradation processes of TPP after mixing with the clay were studied by FTIR analysis and thermogravimetry techniques. Samples include clay, TPP and the blend TPP/clay (1:1 weight). An important result is that the thermal stability of TPP is enhanced when it is mixed with the clay. Figure 3 reveals that the clay itself possesses high thermal stability since the weight loss is small. At the processing temperature, $190^{\circ} \mathrm{C}$, the weight loss of the clay is $7.5 \%$ meanwhile TPP has a weight loss of $14 \%$ but weight loss of only $2.5 \%$ is measured when TPP is intercalated in the clay. This analysis demonstrates that the TPP thermal stability is enhanced when intercalated, avoiding losses by volatilization during processing. By means of TG-FTIR analysis, the gaseous species produced during TPP degradation were measured, and also those generated by the TPP/clay blend (results not shown). Spectra show absence of new compounds to those formed during pure TPP degradation, indicating that TPP intercalated in the clay and pure TPP decompose following a similar 


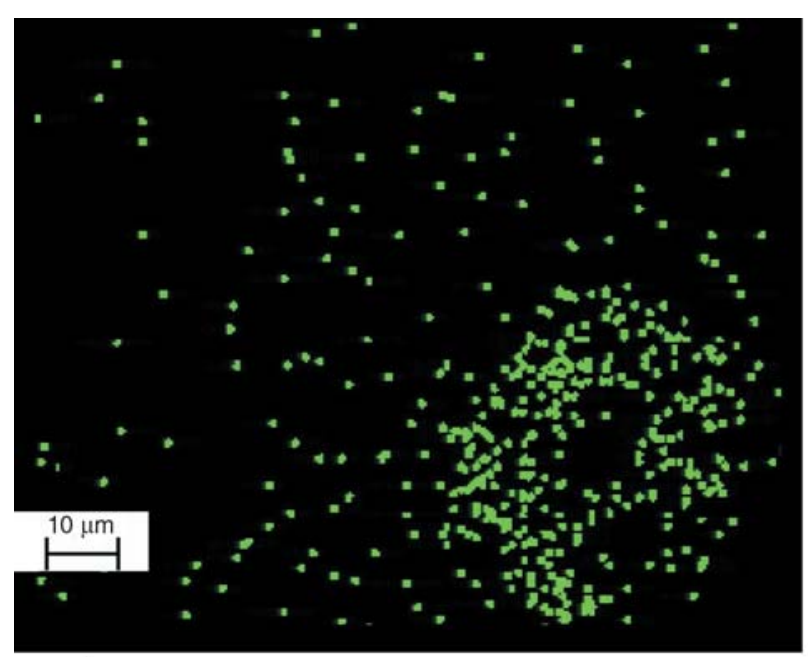

a)

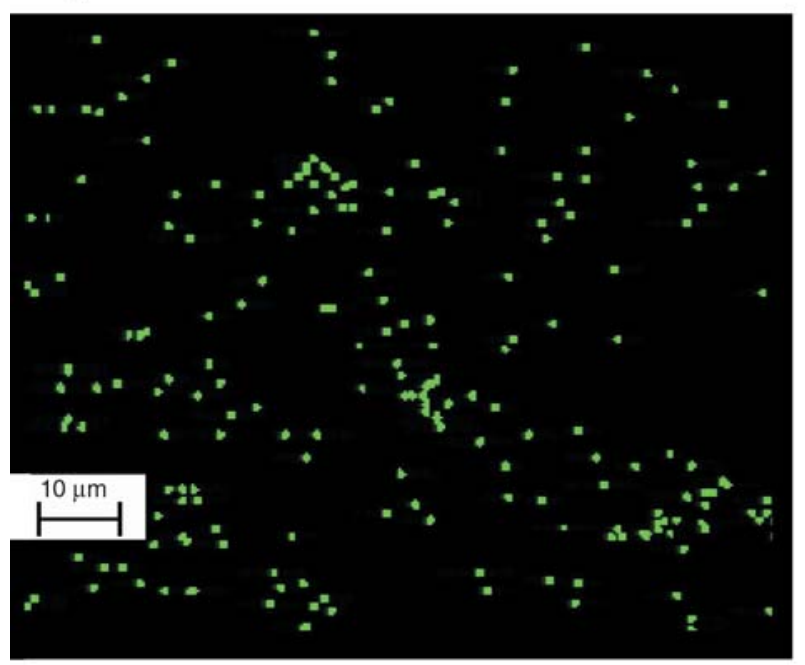

c)

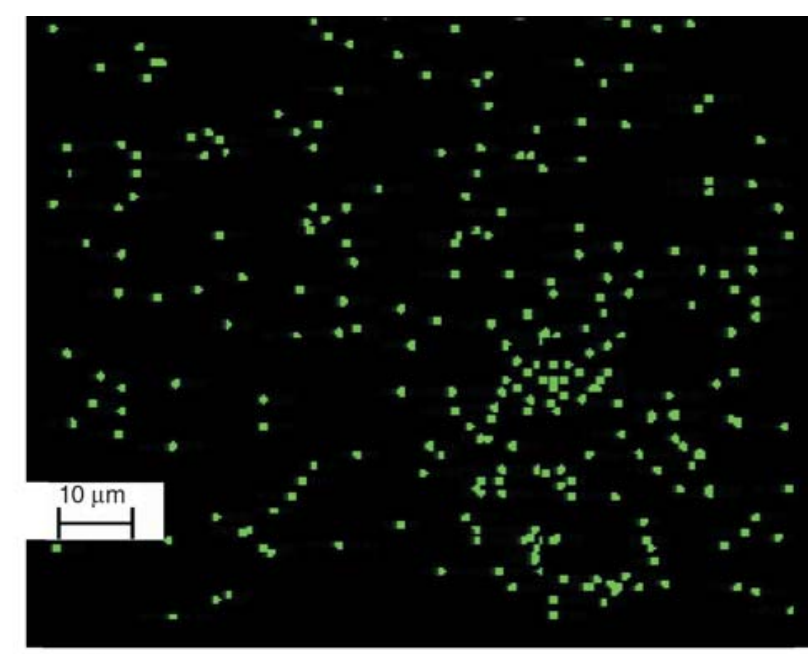

b)

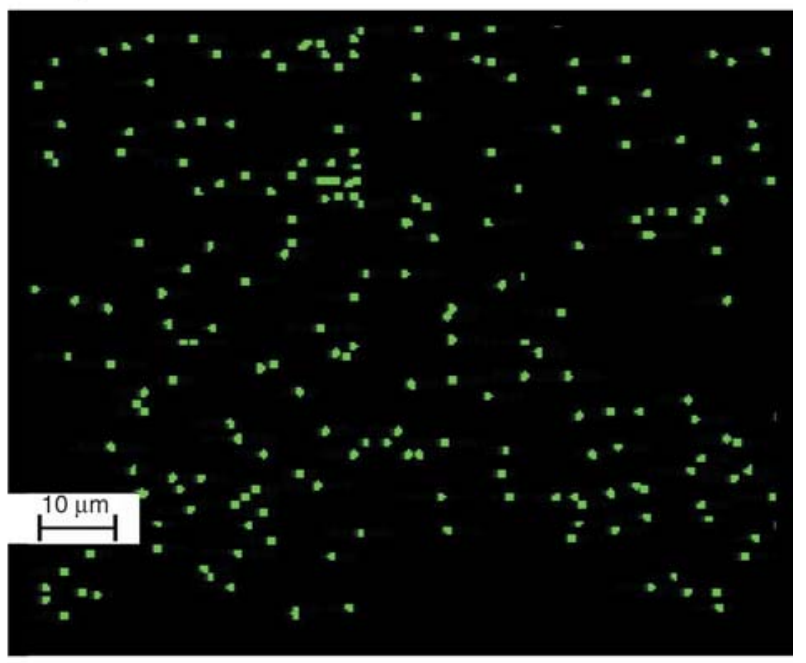

d)

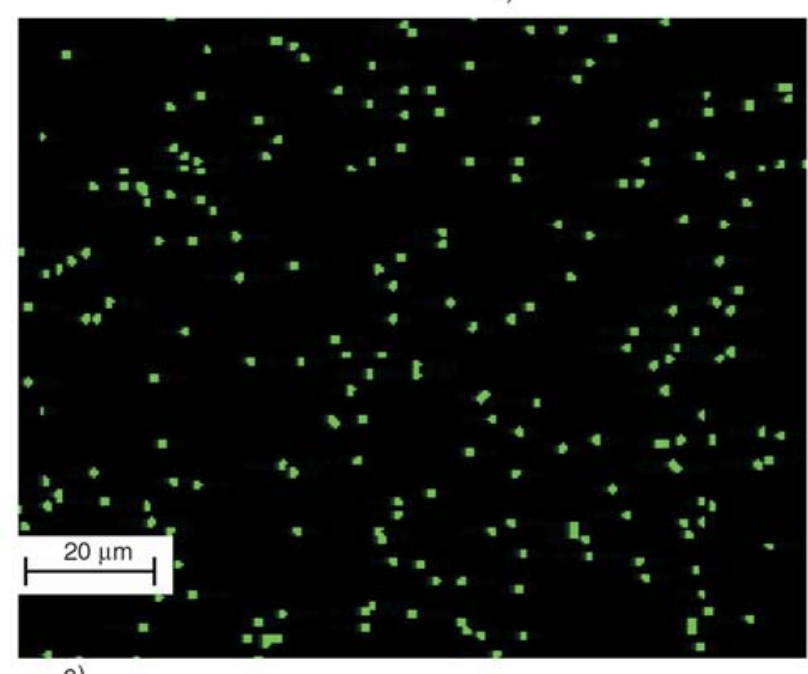

e)

Figure 2. Element mapping for HIPS-TPP/clay blends. a) SS-SMD Silicon particles, b) SS-SMD Phosphorous particles, c) SS-SMD-U Silicon particles, 2d) SS-SMD-U Phosphorous particles, e) CR- TS Silicon particles. Magnification $1000 \mathrm{X}$.

mechanism. Figure 4 presents the residues spectrum after TPP/clay decomposition, showing that only silicon compounds of the clay remain. Compounds containing $\mathrm{Si}-\mathrm{O}$ and $\mathrm{SiO}_{3}^{2-}$ are character- ized in the region of $1100-1000$ and $470-460 \mathrm{~cm}^{-1}$ respectively $[25,26]$. The absorptions at $3437-$ $1631 \mathrm{~cm}^{-1}$ are due to $\mathrm{KBr}$ impurities. 


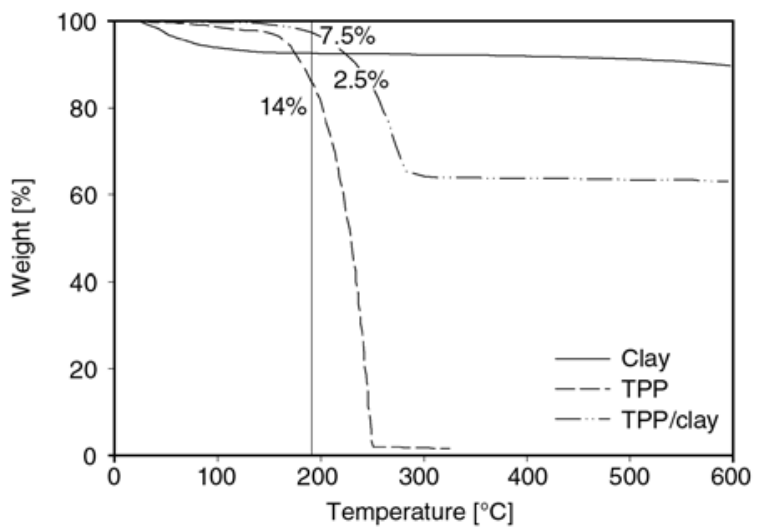

Figure 3. TGA measurements for Clay, TPP and $\mathrm{TPP} / \mathrm{clay}$. Heating rate is $10^{\circ} \mathrm{C} / \mathrm{min}$ under nitrogen atmosphere. Weight loss data at $190^{\circ} \mathrm{C}$.

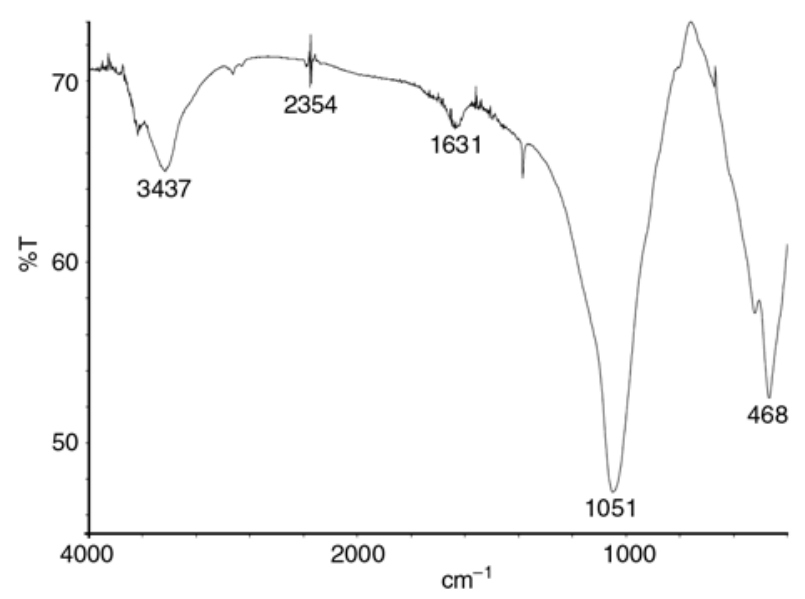

Figure 4. TGA-FTIR residues of TPP/clay (1:1)

\subsection{Behavior under combustion for oxygen index and UL94-V tests}

In Table 1 the oxygen index and UL94-V tests results are disclosed. Both show that the extrusion processes do not substantially influence the flammability properties of the HIPS-TPP/clay blend, since the behavior in combustion is similar to that of pure HIPS and the material continues burning after the first application of the flame (10 seconds). The flame reaches the holding clamp and the material drips and ignites the cotton, so no improvements are observed in UL94 flammability classifi-
Table 1. Oxygen index and UL94-V results

\begin{tabular}{|l|c|c|}
\hline \multicolumn{1}{|c|}{ Material } & $\begin{array}{c}\text { Oxygen } \\
\text { index } \\
{[\%]}\end{array}$ & $\begin{array}{c}\text { UL94 } \\
\text { vertical } \\
\text { position }\end{array}$ \\
\hline HIPS & 18.8 & non classified \\
\hline HIPS-TPP/clay (CR-TS) & 19.2 & non classified \\
\hline HIPS-TPP/clay (SS-SMD) & 19.6 & non classified \\
\hline HIPS- TPP/clay (SS-SMD-U) & 19.4 & non classified \\
\hline
\end{tabular}

(CR-TS), twin screw counter-rotating; (SS-SMD), single screw with the static mixing die; (SS-SMD-U), single screw with the static mixing die and sonication

cations despite the different extrusions processes employed. Oxygen index values are also similar, with variations up to $1.4 \%$ with respect to that of HIPS.

\subsection{Behavior under forced combustion in cone calorimetric test}

Cone calorimetric data are summarized in Table 2. The parameters evaluated were time to ignition, the total heat evolved (THE), the specific extinction area (SEA), the smoke and carbon monoxide yield $(\mathrm{CO})$, and the heat release rate, specially its maximum value, (pkHRR). The heat release rate is an important parameter in fire safety since it determines the fire extent and its rate of propagation. The combustion behavior shows differences depending on the extrusion process. The time to ignition for the three extrusion processes is shorter than that of HIPS, attaining the shortest time in the single-screw with the static mixing die process. This reduction in the ignition time may be attributed to the presence of nanoparticles, which induce larger mobility of the polymer melt by particle alignment with the flow to combustion zone [27, 28 ] and this could be promoting the initiation of the combustion in shorter times. The mobility of the polymer melt is related to the drop in viscosity. This viscosity reduction is enhanced by augmented proportion of low molecular weight polymer molecules formed either by thermal degradation of high

Table 2. Calorimetric cone data

\begin{tabular}{|l|c|c|c|c|c|c|c|c|}
\hline \multicolumn{1}{|c|}{ Material } & $\begin{array}{c}\text { Ignition } \\
\text { time [s] }\end{array}$ & $\begin{array}{c}\text { Residues } \\
{[\mathbf{\%}]}\end{array}$ & $\begin{array}{c}\text { pkHRR } \\
{\left[\mathbf{k W / \mathbf { m } ^ { 2 } ]}\right.}\end{array}$ & $\begin{array}{c}\Delta \mathbf{p k H R R} \\
{[\mathbf{\%}]}\end{array}$ & $\begin{array}{c}\text { THE } \\
{\left[\mathbf{M J} / \mathbf{m}^{2}\right]}\end{array}$ & $\begin{array}{c}\text { SEA } \\
{\left[\mathbf{m}^{2} / \mathbf{k g}\right]}\end{array}$ & $\begin{array}{c}\text { CO } \\
{[\mathbf{g} / \mathbf{g}]}\end{array}$ & $\begin{array}{c}\Delta \mathbf{C O} \\
{[\mathbf{\%}]}\end{array}$ \\
\hline HIPS & 78 & 0 & 793 & - & 87 & 929 & 82 & - \\
\hline HIPS-TPP/clay (CR-TS) & 42 & 5 & 814 & +3 & 75 & 773 & 74 & -10 \\
\hline HIPS-TPP/clay (SS-SMD) & 37 & 4 & 693 & -13 & 89 & 1320 & 84 & +3 \\
\hline HIPS-TPP/clay(SS-SMD-U) & 49 & 4 & 724 & -6 & 87 & 1339 & 86 & +6 \\
\hline
\end{tabular}

(CR-TS), twin screw counter-rotating; (SS-SMD), single screw with the static mixing die; (SS-SMD-U), single screw with static mixing die and sonication 
molecular weight polymer molecules or by increasing concentration due to the adhesion of the high molecular weight chains to the clay platelets. The low molecular weight compounds contribute to rapidly generate volatile compounds that may be burned at the initial stage of the ignition process. In the case of the HIPS-TPP/clay system, the two blends obtained in the single-screw process present lower viscosity along the entire shear-rate range. This enhanced fluidity may be related to the lower ignition time. The char yield is similar in the three samples (4-5\%) which closely corresponds to the clay concentration in the samples.

The heat-release rate results of the HIPS-TPP/clay blend are shown in Figure 5. The pkHRR is reduced by $13 \%$ with respect to that of HIPS in the single screw process with the static mixing die. In the blend obtained with the sonication system, the pkHRR is reduced by $6 \%$. On the contrary, in the twin screw extrusion process, an increase of $3 \%$ is measured but the average specific mass loss rate decreases by $5 \%$ (not shown). The reduction in the heat release rate can then be correlated with the TPP and clay particle dispersion and distribution in the polymer. As the particle dispersion improves using the mixing die, the generation of a char layer at the surface of the melt under combustion is likely, acting as a barrier-insulator and hence retarding energy transfer and mass loss. However, this layer is weak, since it is not formed by stable residues at the decomposition temperature, and hence they are burned during the combustion process, this is depicted on Figure 5 where the shape of the curve shows two slope changes on line behavior. Regarding the effect of TPP in the combustion process, it apparently acts as a flame-retardant agent in the gas phase, since the smoke production (SEA) increases by $40 \%$ and the $\mathrm{CO}$ yield increases by 3 and $6 \%$ for the two single screw extrusion processes (see Table 2). It is feasible that the increasing smoke production is caused by partially-aromatized product decomposition during

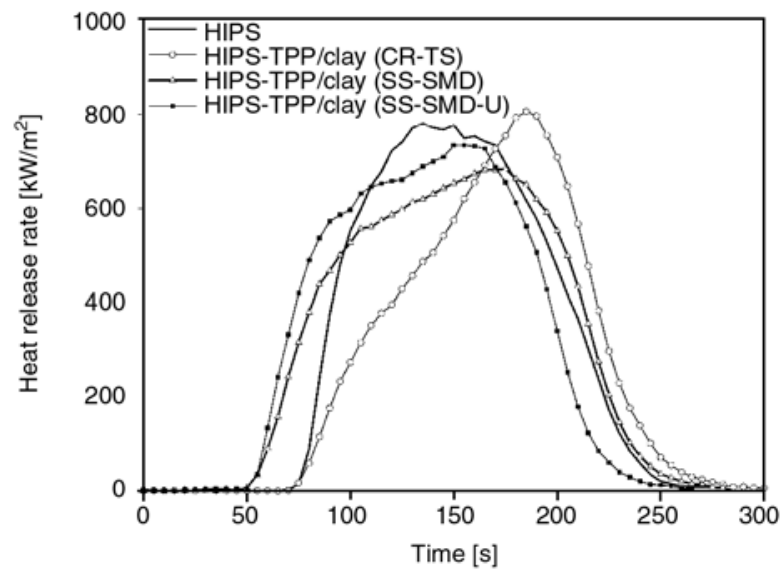

Figure 5. Heat release rate versus time for the HIPSTPP/clay blend. (CR-TS): twin screw counterrotating. (SS-SMD): single screw with the static mixing die. (SS-SMD-U): single screw with the static mixing die and sonication.

char formation that might volatilize before complete charring. Meanwhile, HIPS and the HIPSclay system share the same reduced smoke production.

The particle distribution affects substantially the heat release rate. The clay particles containing intercalated TPP must have a good dispersion to obtain an effect on the heat release rate. In fact, reports [29] on fire behavior of nanocomposites have pointed out that poor dispersion at the micrometer level is unable to diminish the heat release rate substantially. The absence of nanometer-scale particles is related to an increase in the heat release rate.

\subsection{Thermal stability}

TGA under nitrogen atmosphere with a heating rate of $10^{\circ} \mathrm{C} / \mathrm{min}$ was used to assess the thermal stability of the HIPS-TPP/clay blend produced under the three extrusion methods. The results are reported in Table 3 and in Figure 6. Table 3 shows the initial degradation temperature, corresponding to the temperature at which the weight loss of the sample attains $10 \%\left(T_{10}\right)$, the main degradation tempera-

Table 3. Degradation temperature and percentage of residues. HIPS-TPP/clay blend

\begin{tabular}{|l|c|c|c|}
\hline \multicolumn{1}{|c|}{ Sample } & $\mathbf{T}_{\mathbf{1 0}}\left[{ }^{\circ} \mathbf{C}\right.$ ] & T $_{\mathbf{5 0}}\left[{ }^{\circ} \mathbf{C}\right]$ & Residues [\%] \\
\hline HIPS & 382 & 403 & 1.5 \\
\hline HIPS-TPP/clay (CR-TS) & 370 & 403 & 4.4 \\
\hline HIPS-TPP/clay (SS-SMD) & 377 & 408 & 4.8 \\
\hline HIPS-TPP/clay (SS-SMD-U) & 379 & 409 & 5.0 \\
\hline
\end{tabular}

(CR-TS), twin screw counter-rotating; (SS-SMD), single screw with the static mixing die (SS-SMD-U); single screw with the static mixing die and sonication 


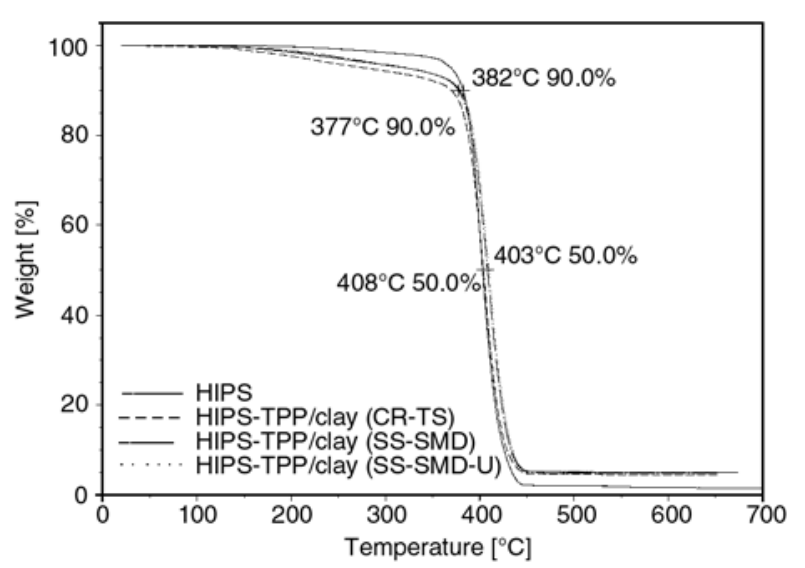

Figure 6. TGA of HIPS-TPP/clay. Same caption as in Figure 5.

ture $\left(T_{50}\right)$ and the percentage of residues remaining at $600^{\circ} \mathrm{C}$. A lower initial degradation temperature is preferred since the formation of the char layer occurs earlier, but a higher main degradation temperature is sought to achieve better thermal stability.

Figure 6 shows the mass loss versus temperature, revealing that the sample produced in the twinscrew process presents lower initial degradation temperature $\left(-12^{\circ} \mathrm{C}\right)$ with respect to that of HIPS, but it presents the same $T_{50}$ of HIPS. This contrasts with the samples produced in the single-screw processes, where $T_{10}$ is lower, but $T_{50}$ increases $5-6^{\circ} \mathrm{C}$ with respect to that of HIPS. Thermal stability is enhanced by a small extent with better $\mathrm{TPP} /$ clay particle dispersion produced in the mixing die.

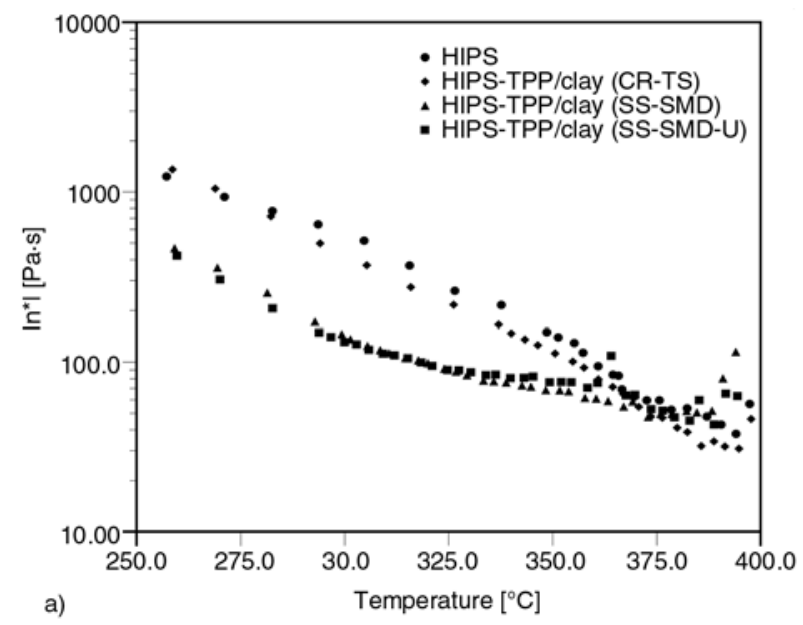

\subsection{Rheological properties}

In the HIPS-TPP/clay blend, Figure 7 reveals the influence of the extrusion processes on the shear viscosity. The single-screw process with the mixing die affects the viscosity strongly, diminishing it with respect to that of HIPS and that of the twinscrew process throughout the range of shear rates. Plasticizing effects of TPP are discarded because the same proportion of TPP is used in all blends. Polymer degradation due to the strong flow in the die is possible. In the large shear rate range, it has been reported that with enhanced dispersion, the particles promote increasing orientation of the blend as the shear rate augments [30], and this effect induces enhanced flow of the polymer melt. Figure 8a shows again the effect of the mixing die on the temperature dependence of the complex viscosity. Viscosity is lower in the blend produced

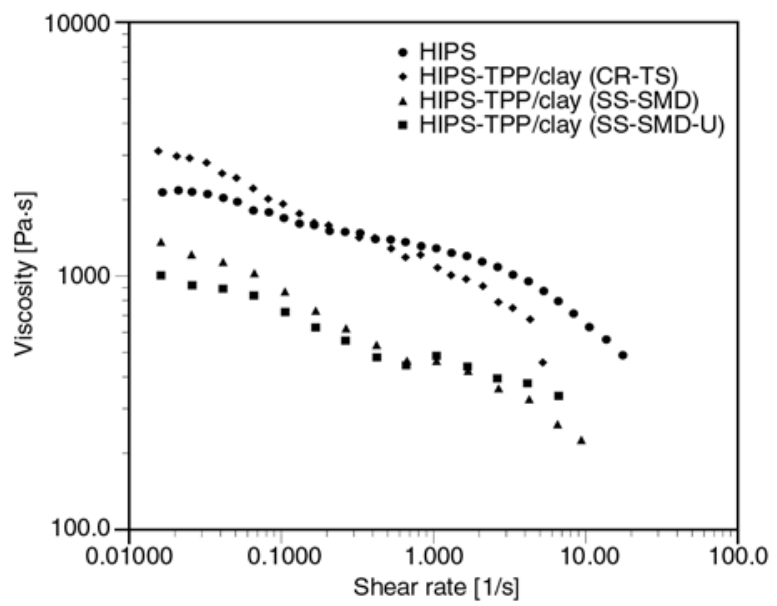

Figure 7. Shear viscosity as a function of the shear rate of the HIPS-TPP/clay blend. Same caption as in Figure 5.

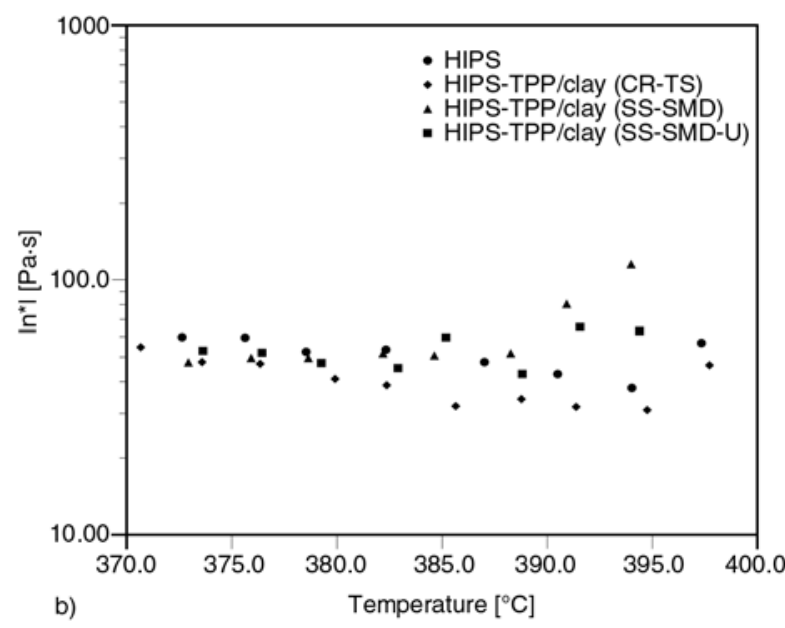

Figure 8. HIPS-TPP/clay blend. a) Complex viscosity versus temperature, b) magnification of the complex viscosity plot. Test conditions: angular frequency $1 \mathrm{rad} / \mathrm{s}$ and rate of $10^{\circ} \mathrm{C}$. Same caption as in Figure 5. 
using the mixing die at low temperatures, although the slope is smaller than that of the blend produced in the twin-screw process. Upon increasing temperature, the curves meet. In the high temperature range, the sudden increase of the complex viscosity at a critical temperature signals the initial stage of thermal degradation and formation of charring material [31]. This increase occurs at lower temperature for the samples obtained using the mixing die. Figure $8 \mathrm{~b}$ shows a zoom of the last segment of the curves for HIPS and the twin-screw process. The degradation temperature in this case is $397^{\circ} \mathrm{C}$, whereas with the mixing die single-screw process this is $382^{\circ} \mathrm{C}$. The decrease in the initial degradation temperature by rheological measurements agrees with the results of the thermogravimetric analysis, where the initial decomposition temperature decreases with respect to that of HIPS when using the single screw device. Enhanced particle dispersion induces larger mobility and enhanced melt flow.

Figures $9 a, 9 b$ and $9 c$ show the influence of the extrusion processes on the viscoelastic properties of the HIPS-TPP/clay blend. The storage modulus versus frequency of the blend produced in the single screw processes (with and without sonication) is similar, demonstrating a negligible effect of the sonication on the elasticity of the blends. Throughout the frequency range the elasticity of the blend produced in the single screw process is lower than the elasticity of the blend produced in the twinscrew process. At low frequencies $(0.1-1.0 \mathrm{rad} / \mathrm{s})$ the modulus of these blends decreases with respect to that of HIPS, revealing a degradation of the system as it passes through the die or an enhanced fluid-like behavior brought about by the presence of the particles. In all cases, the effect of the clay particles is apparent, as the slope of $G^{\prime}$ at small frequencies decreases from the limiting value of 2 . The storage modulus in samples subjected to the twin screw process shows no difference with that of HIPS at low frequencies, and an increase in the high frequency range due to increased entanglement density or particle-polymer interactions.

The loss modulus of samples produced with the mixing die decreases with respect to that of HIPS in the low frequency range, similarly to the behavior of the shear viscosity (not shown). In the sample produced via the twin screw process, the loss mod-
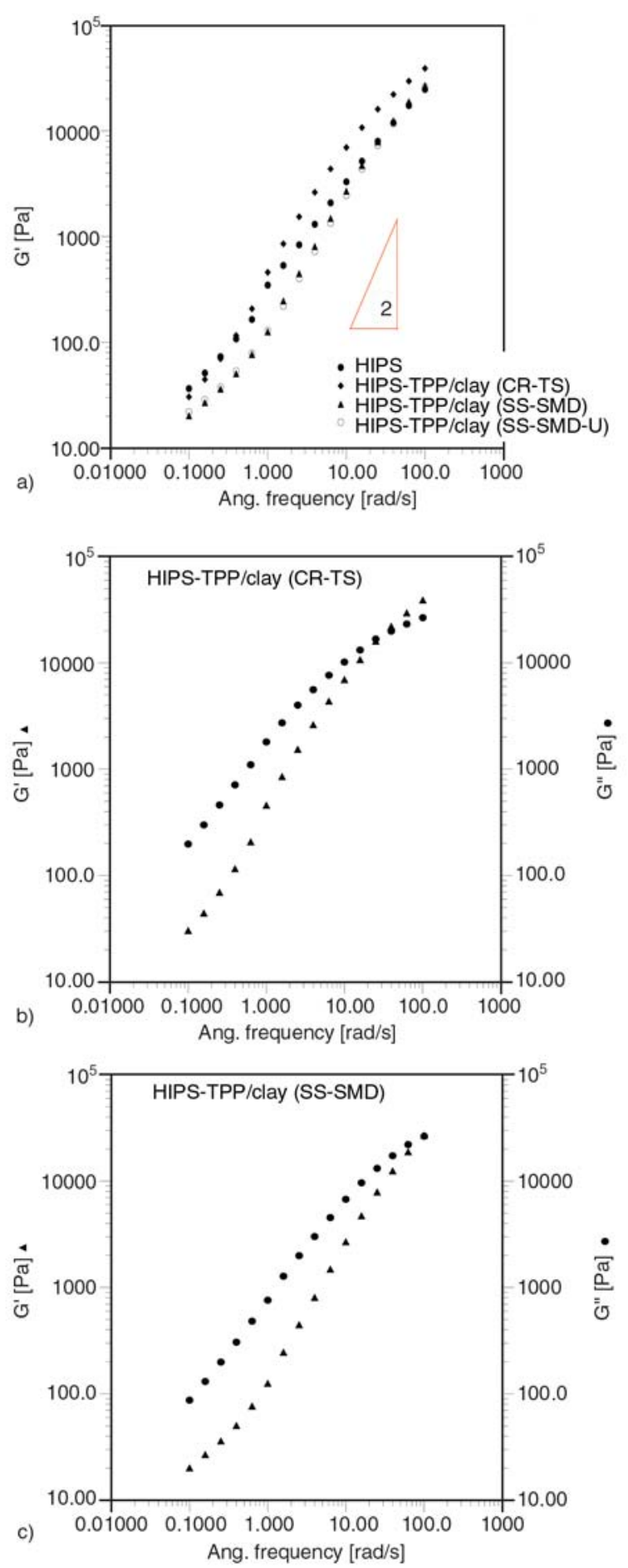

Figure 9. HIPS-TPP/clay blend. a) Storage modulus versus frequency. Same caption as in Figure 5. b) Storage and loss modulus versus frequency. Twin-screw process. c) Storage and loss modulus versus frequency. Single screw process.

ulus increases with respect to that of HIPS, again in agreement with the shear viscosity results.

In Figures $9 \mathrm{~b}$ and $9 \mathrm{c}, G^{\prime}$ and $G^{\prime \prime}$ versus frequency for samples made with the twin-screw and singlescrew processes are shown, respectively. The 
Table 4. Mechanical properties HIPS-TPP/clay blends

\begin{tabular}{|l|c|c|c|c|}
\hline \multicolumn{1}{|c|}{ Extrusion process } & $\begin{array}{c}\text { Tensile strength } \\
{[\mathbf{M P a}]}\end{array}$ & $\begin{array}{c}\text { Young's modulus } \\
{[\mathbf{M P a}]}\end{array}$ & $\begin{array}{c}\text { Strain at break } \\
{[\mathbf{\%}]}\end{array}$ & $\begin{array}{c}\text { Izod impact } \\
{[\mathbf{J} / \mathbf{m}]}\end{array}$ \\
\hline HIPS & 26 & 1017 & 35 & 161 \\
\hline HIPS-TPP/clay (CR-TS) & 20 & 1017 & 12 & 166 \\
\hline HIPS-TPP/clay (SS-SMD) & 25 & 930 & 7 & 105 \\
\hline HIPS-TPP/clay (SS-SMD-U) & 27 & 989 & 8 & 98 \\
\hline
\end{tabular}

(CR-TS), twin screw counter-rotating; (SS-SMD), single screw with the static mixing die (SS-SMD-U); single screw with the static mixing die and sonication

crossing point of both moduli signals the characteristic frequency of the systems, the reciprocal of which is the main relaxation time of the blend. It is apparent that the relaxation time of the blend produced in the single-screw process is smaller $(0.01 \mathrm{~s})$ than that of the blend that underwent the twinscrew process $(0.033 \mathrm{~s})$. Again, a smaller relaxation time is associated to an enhanced fluid-like behavior in shear flow when using the mixing die.

\subsection{Mechanical properties}

Table 4 discloses the mechanical properties under tension and impact tests of the HIPS-TPP/clay blends. Similar behavior of the blends produced using the mixing die reveals no influence of sonication. Young's modulus, strain at break and impact resistance show a decrease as compared to the HIPS values, except the tensile strength, revealing polymer degradation produced in the mixing die. This is absent in samples produced in the twin screw process, where the mixing die is not used, although the strain at break is reduced.

\section{Conclusions}

This study demonstrates that the HIPS-TPP/clay blend properties (flammability, combustion, thermal, rheological and mechanical) depend on the dispersion and distribution of the particles in the polymer matrix. Three extrusion processes were considered to produce different degrees of particle dispersion. When this is good (single-screw with the static mixing die process), the peak in the heat release rate diminishes in cone-calorimetric tests. The contrary occurs (twin screw process) when particle dispersion is not uniform. The sonication system with power and frequency employed has negligible effect in clay dispersion, and in the rheological and mechanical properties. A positive result is the reduction in the heat release rate due to good dispersion, but the negative effect is a reduction of the mechanical and impact properties of the blend when is processed with the mixing die

Mechanical and rheological properties are modified with respect to those of HIPS when the static mixing die is used, revealing an effect (lower viscosity) produced by degradation of the polymer as the blend passes through the die.

The TPP volatilization is reduced when it is mixed with the clay at the processing temperature, effectively increasing the efficiency of TPP as flameretardant agent.

Results indicate an improved reduction of flammability associated to a better dispersion of the clay and TPP in HIPS due to the extrusion process used, although the price is the reduction of the mechanical properties by degradation. The paper contributes to the understanding of the balance sought between mechanical properties and reduction in flammability

\section{Acknowledgements}

We thank the financial support from the PAPIIT-UNAM project IN-103207/19 and also we acknowledge the technical support of L. Baños, M. Canseco, F. Calderas and E. Sanchez from IIM-UNAM, and F. Canta, M. Lavaselli, A. Sarra, E. Arrobio and C. Ciccarelli from Politecnico di Torino.

\section{References}

[1] ASTM D2863 (EN ISO 4589): Plastics. Thermal properties. Standard test method for measuring the minimum oxygen concentration to support candle-like combustion of plastics (oxygen index) (1999).

[2] ASTM D3801: Plastics. Thermal properties. Standard test method for measuring the comparative extinguishing characteristics of solid plastics in a vertical position, measuring (1999).

[3] ASTM E1354 (EN ISO 5660): Plastics. Standard test method for heat and visible smoke release rates for materials and products using an oxygen consumption calorimeter (1999). 
[4] Schartel B., Bartholmai M., Knoll U.: Some comments on the use of cone calorimeter data. Polymer Degradation and Stability, 88, 540-547 (2005).

[5] Schartel B., Hull T. R.: Development of fire-retarded materials-interpretation of cone calorimeter data. Fire and Materials, 31, 327-354 (2007).

[6] Sprenkle W. E., Southern J. H.: Rubber-modified polystyrene impact as a function of flame-retardant additive solubilization. Journal of Applied Polymer Science, 26, 2229-2238 (1981).

[7] Utevski L., Scheinker M., Georlette P., Lach S.: Flame retardancy in UL-94 V-0 and in UL-94 5VA high impact polyatyrene. Journal of Fire Sciences, 15, 375-389 (1997).

[8] Yang C-P., Sheen B-S.: Effect of tetrabromobisphenol. A diallyl ether on the flame retardancy of high impact strength polystyrene. Journal of Applied Polymer Science, 37, 3185-3194 (1989).

[9] Song J. H.: Typical flame retardant/additive chemicals for commercial FR-HIPS and FR-ABS resins. Journal of Vinyl and Additive Technology, 1, 196-204 (1995).

[10] Granzow A., Savides C.: Flame retardancy of polypropylene and impact polystyrene: phosphonium bromide/ammonium polyphosphate system. Journal of Applied Polymer Science, 25, 2195-2204 (1980).

[11] Levchik S. V., Bright D. A., Moy P., Dashevsky S.: New developments in fire retardant non-halogen aromatic phosphates. Journal of Vinyl and Additive Technology, 6, 123-128 (2000).

[12] Gilman J. W.: Flammability and thermal stability studies of polymer layer-silicate (clay) nanocomposites. Applied Clay Science, 15, 31-49 (1999).

[13] Gilman J. W., Jackson C. L., Morgan A. B., Harris R. Jr., Manias E., Giannelis E. P., Wuthenow M., Hilton D., Philips S. H.: Flammability properties of polymerlayered-silicate nano-composites. Polypropylene and polystyrene nanocomposites. Chemistry of Materials, 12, 1866-1873 (2000).

[14] Porter D., Metcalfe E., Thomas M. J.: Nanocomposite fire retardants- A review. Fire and Materials, 24, 4552 (2000).

[15] Morgan A. B.: Flame retarded polymer layered silicate nanocomposites: A review of commercial and open literature systems. Polymers for Advanced Technology, 17, 206-217 (2006).

[16] Morgan A. B., Wilkie C. A.: Flame retardant polymer nanocomposites. John Wiley and Sons, Hoboken (2007).

[17] Okamoto M.: Polymer/clay nanocomposites. in 'Encyclopedia of nanoscience and nanotechnology' (Ed: Nalwa H. S.) American Scientific Publishers, Stevenson Ranch, vol 8, 791-843 (2004).

[18] Gilman J. W., Kashiwagi T.: Polymer-layer silicate nanocomposites with conventional flame retardants. in 'Polymer-clay nanocomposites.' (eds.: Pinnavaia T. J., Beall G. W.) John Wiley and Sons, Baffins Lane, vol 10, 193-206 (2000).
[19] Dennis H. R., Hunter D. L., Chang D., Kim S., White J. L., Cho J. W., Paul D. R.: Effect of melt processing conditions on the extent of exfoliation in organoclaybased nanocomposites. Polymer, 42, 9513-9522 (2001).

[20] Wang K., Liang S., Du R., Zhang Q., Fu Q.: The interplay of thermodynamics and shear on the dispersion of polymer nanocomposite. Polymer, 45, 7953-7960 (2004).

[21] Lertwimolnum W., Vergnes B.: Influence of compatibilizer and processing conditions on the dispersion of nanoclay in a polypropylene matrix. Polymer, 46, 3462-3471 (2005).

[22] Peltola P., Välipakka E., Vuorinen J., Syrjälä S., Hanhi K.: Effect of rotational speed of twin screw extruder on the microstructure and rheological and mechanical properties of nanoclay-reinforced polypropylene nanocomposites. Polymer Engineering and Science, 46, 995-1000 (2006).

[23] Modesti M., Lorenzetti A., Bon D., Besco S.: Effect of processing conditions on morphology and mechanical properties of compatibilized polypropylene nanocomposites. Polymer, 46, 10237-10245 (2005).

[24] Sanchez-Olivares G., Sanchez-Solis A., Manero O.: Effect of montmorillonite clay on the burning rate of high-impact polystyrene. International Journal of Polymeric Materials, 57, 245-257 (2008).

[25] Lin-Vien D., Colthup N. B., Fateley W. G., Grasselli J. G.: The handbook of infrared and Raman characteristic frequencies of organic molecules. Academic Press Inc., San Diego (1991).

[26] Bebthley F. F., Smithson L. D., Rozek A. L.: Infrared spectra and characteristic frequencies. Interscience Publishers, New York (1968).

[27] Sanchez-Solis A., Garcia-Rejon A., Manero O.: Production of nanocomposites of PET-monmorillonite clay by an extrusion process. Macromolecular Symposia, 192, 281-292 (2003).

[28] Sanchez-Solís A., Romero-Ibarra I., Estrada M. R., Calderas F., Manero O.: Mechanical and rheological studies on polyethylene terephthalate-montmorillonite nanocomposites. Polymer Engineering and Science, 44, 1094-1102 (2004).

[29] Costache M. C., Heidecker M. J., Manias E., Camino G., Frache A., Beyer G., Gupta R. K., Wilkie C.: The influence of carbon nanotubes, organically modified montmorillonites and layered double hydroxides on the thermal degradation and fire retardancy of polyethylene, ethylene-vinyl acetate copolymer and polystyrene. Polymer, 48, 6532-6545 (2007).

[30] Lim Y. T., Park O. O.: Rheological evidence for the microstructure of intercalated polymer/layered silicate nanocomposites. Macromolecular Rapid Communications, 21, 231-235 (2000).

[31] Marosfői B., Matkó Sz., Anna P., Marosi Gy.: Fire retarded polymer nanocomposites. Current Applied Physics, 6, 259-261 (2006). 